\title{
Highly Fluorescent Carbon Nanoparticle: An Emerging Bioimaging Intervention
}

\author{
Debbethi Bera ${ }^{a, b}$, Kunal Pal ${ }^{c, d}$, Parimal Karmakar ${ }^{c}$, Sukhen Das ${ }^{a, b}$, Papiya Nandy ${ }^{a^{*}}$
}

\author{
${ }^{a}$ Centre for Interdisciplinary Research and Education \\ 404B, Jodhpur Park, Kolkata-700068, India \\ ${ }^{b}$ Department of Physics, Jadavpur University \\ Kolkata-700032, India \\ ${ }^{c}$ Department of Life Science and Biotechnology, Jadavpur University \\ Kolkata-700032, India \\ ${ }^{d}$ Division of Molecular Medicine and Centre for Translational Research, \\ Bose Institute, Kolkata-700056, India
}

*Corresponding author Email Id: pnanady00@gmail.com

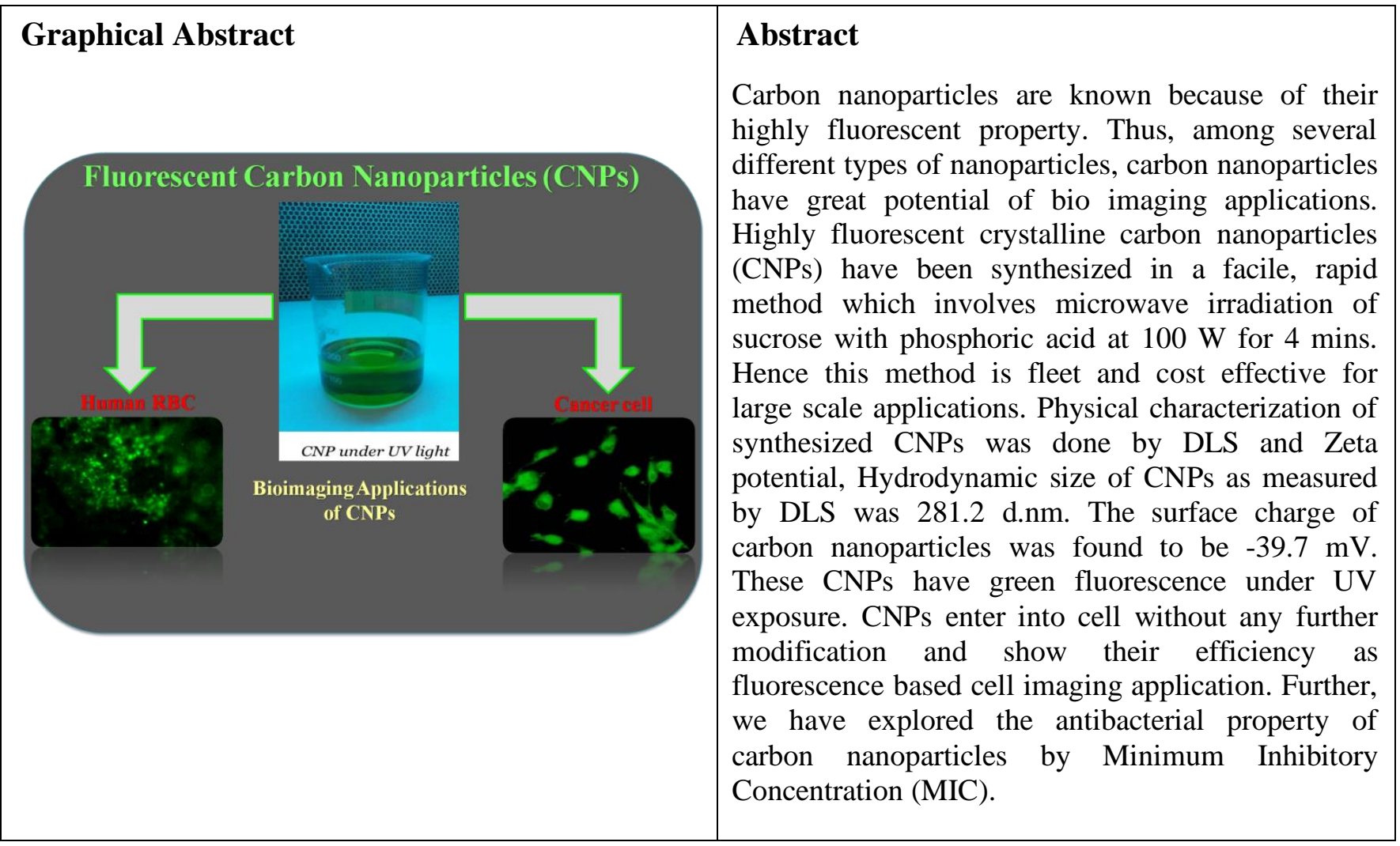


Key Words: Carbon nanoparticles, Fluorescence, Cell labeling, RBC, Breast Cancer cell.

\section{Introduction}

The fluorescence property of carbon nanoparticles (CNPs) proved its potential in functionalized manner such as carbon nanotubes and fullerenes. Biocompatiblity and chemically inert property of CNPs increased its utilization in biological labeling, bioimaging and other different optoelectronic device applications [1-18]. These carbon nanoparticles have more advantages over conventional cadmium based quantum dots [19]. CNPs also aid in detection, diagnosis and treatment in human cancers and explore a new dimension of nano-oncology [20].

Semiconductor fluorescent quantum dots, nanocrystals, nanoparticles, nanocantilevers and nanoprobes conjugated with antibodies facilitate in labeling and quantifying the biomarker or targeted protein expressed on cancerous cells [21]. These types of nanotechnology-based techniques efficiently increased the specification detection and quantification of biomarker from minimal samples, tailoring swift and targeted therapy [22].

In addition, the effects of an individual treatment on expression of the target protein can be monitored before and after treatment, and provide a rapid method to measure the efficacy of a targeted therapy.

An ample range of fluorescent carbon particle are synthesized in several manners e.g. nitrogen doped diamond gives red fluorescence [1], candle soot derived particle [8] or thermal decomposition method $[11,12]$ or laser ablation method [4] produced particles with multiple colours and Octadecylamine functionalized diamond nanoparticle showed blue fluorescence [13]. However, they have their respective shortcomings such as quantum yield are $<1 \%[8,9]$ with few exceptions $[4,13]$ followed by cumbersome and inefficient synthetic methods. For example, in the high energy ion beam radiation based method, it is difficult to introduce a large number of point defects into ultra-fine Nano-carbon particles $(<10 \mathrm{~nm})$ for bright luminescence [1,3]. Thermal decomposition based methods produce low yield of soluble and fluorescent particle with a significant fraction of insoluble product $[10,11,13]$. Soot based synthesis produce particle mixture of different colours and isolation of different coloured particles by gel electrophoresis is a difficult task [8]. Recent report showed that surface passivation can lead to a significant increase in fluorescence quantum yield (4-15\%) however exact mechanism is not yet clear [4,13]. Thus facile, competent and large scale synthesis of fluorescent carbon nanoparticle 
and their isolation, purification and functionalization are very important. Among all these synthetic methods, thermal decomposition of organic compound is simple and straight forward [8].

We have synthesized fluorescent carbon nanoparticles via a facile, cost effective synthetic route and have thoroughly characterized the nanoparticles with the help of XRD, FTIR and UV-Vis spectrophotometry. We have then evaluated their activity against pathogenic bacterial cells, human cancerous cells as well as normal human cells. Our results confirm that these synthesized nanoparticles show excellent biocompatibility towards the normal lung fibroblast cells. Furthermore, these fluorescent nanoparticles were then used to label the RBCs and the breast cancer cells, MDA-MB 468. Our results depict that these nanoparticles are able to penetrate within these human biological systems even without any functional modifications. Therefore these synthesized fluorescent carbon nanoparticles have emerged as promising imaging tool for applications in different biomedical fields.

\section{Materials and Methods}

\section{Materials}

Sucrose, Ortho-Phosphoric Acid (88\%), MDA-MB-468 cell line DMEM with 10\% Fetal Bovine Serum (FBS), MTT [3-(4,5-dimethylthiazole-2-yl)-2,5- diphenyltetrazoliumbromide [SRL], Extraction Buffer (Isopropanol, 12N HCl, Triton X), Luria Broth and all the chemicals and reagents required for bacterial culture media, different chemicals and reagents used for biological purposes were pruchased from Merck Ltd, and SRL Pvt. Ltd, Mumbai, India at the highest grade available. All the reagents were used without further purification. Deionised (Millipore) water was used throughout the experiment with resistivity at least $18 \mathrm{M} \Omega-\mathrm{cm}$. All the glass-wares used in our experiments were cleaned with aqua regia solution followed by rinsing with ultrapure water.

\section{Bacterial strain and Cell line}

Bacterial strains used in our study are gram negative Escherichia coli 443 and gram positive Staphylococcus aureus 740. Bacterial strains were procured from the Microbial Type Culture Collection (MTCC), IMTECH, Chandigarh, India.

MDA-MB-468 and and WI38 (human lung fibroblast) cell lines were procured from the Central Cell Repository of National Center for Cell Science (NCCS), Pune, India.

\section{Methods}

\section{Synthesis of carbon nanoparticles (CNPs)}

A solution of sucrose $(1 \mathrm{~g})$ was dissolved in water $(4 \mathrm{ml})$ followed by addition of ortho-phosphoric acid 
$(88 \%)(20 \mathrm{ml})$. This mixture was incinerated at microwave for 4 mins at $100 \mathrm{~W}$. Later the colourless solution gradually turned to brownish-black through yellow. The solution was allowed to stand at room temperature to cool. $50 \mathrm{ml}$ water was added and again allowed to stand for few minutes. Then, a brownish-black precipitate (CNPs) was obtained, which was collected by centrifugation at $4000 \mathrm{rpm}$ for 10 mins. The CNPs was purified by washing several times with distilled water followed by centrifugation. The sample was finally dried at $40^{\circ} \mathrm{C}$ in a vacuum oven.

\section{Physical characterizations of carbon nanoparticles}

To observe the crystalline property of Carbon nanoparticles, X-ray diffraction (XRD) pattern are analysed using the Model D8, Bruker AXS, Wincosin, USA with a voltage of $40 \mathrm{kv}$ having a scan

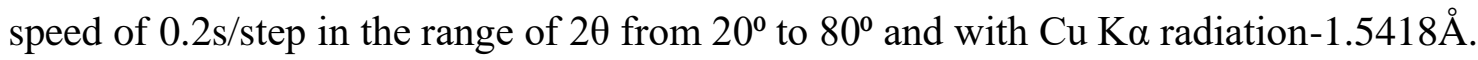

To investigate the functional groups in the biomolecules possibly present in the material, we have examined the Fourier transform infrared spectroscopy (FTIR) with the help of FTIR-8400S (Shimadzu) between the wavelengths of $400 \mathrm{~cm}^{-1}$ and $4000 \mathrm{~cm}^{-1}$.

To measure the absorbance spectra of CNPs at wavelength region of 250-800 nm, Ultraviolet-visible spectrophotometer were used (Bio-tek, India). To determine the size distribution of fluorescent carbon nanoparticles Dynamic light scattering (DLS) were studied by employing Zetasizer (NANO ZS90, Malvern Instruments Ltd., UK)

\section{Peripheral Blood Mononuclear Cell (PBMC) and RBC isolation}

$10 \mathrm{~mL}$ human blood sample was taken in a $50 \mathrm{~mL}$ falcon. Then, $20 \mathrm{~mL}$ PBS was added and the mixture was flashed. After that $3 \mathrm{~mL}$ of Ficoll was added to above solution. Then it was centrifuged at 2,000 rpm for 30 mins at $20^{\circ} \mathrm{C}$ in a swinging-bucket rotor. After centrifugation PBMC is extracted from the blood sample and PBMC layer was taken in a 50ml falcon and made the volume to $30 \mathrm{ml}$ with PBS buffer. From PBMC layer and PBS solution we isolate RBC layer and collected in a $5 \mathrm{ml}$ falcon.

\section{Analysis of antibacterial activity of CNPs}

E. coli strains were overnight cultured on Luria Broth at $37^{\circ} \mathrm{C}$. Next day fresh culture was prepared from the overnight E.coli culture. A sterilized CNPs stock concentration of $2 \mathrm{mg} / \mathrm{mL}$ was prepared. The growth of bacteria was monitored, by treatment of previously prepared fresh culture with different

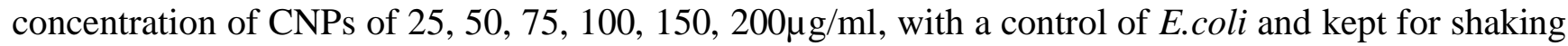
in incubator at $37^{\circ} \mathrm{C}$. Next day, measurement of the optical density (OD) at $600 \mathrm{~nm}$ was taken of these treated E.coli along with the control [25,26,27]. 


\section{Cytotoxicity Assay}

All the cell lines were cultured in the presence of Dulbecco's Modiefied Eagles Media (DMEM) supplemented with $10 \%$ FBS, 1mM sodium pyruvate, $2 \mathrm{mM}$ L-glutamine, non-essential amino acids, in the presence of antibiotic solution comprising of $100 \mathrm{mg} / \mathrm{L}$ penicillin and $100 \mathrm{mg} / \mathrm{L}$ streptomycin. The cells were grown in a humidified atmosphere at a temperature of $37^{\circ} \mathrm{C}$ in presence of $5 \% \mathrm{CO}_{2}$. Cells were seeded in 24 well plates and were then treated with carbon nanoparticles at concentrations of $10,50,100,150,200,300 \mu \mathrm{g} / \mathrm{ml}$. After treatment cells were washed properly with 1 XPBS and then 3(4,5-dimethylthiazol-2-yl)-2,5-diphenyl tetrazolium bromide (MTT) was added and was kept for 3 hrs at $37 \mathrm{C}$. The supernatant was thrown away and 500 $\mu 1$ of extraction buffer was added and shaken for 10 minutes in orbital shaker. The optical density was measured with a UV visible spectrophotometer (synergy) at 570nm [28,29].

\section{Cell labelling of RBC using CNPs}

The isolated RBC was treated with $50 \mu \mathrm{l}$ of carbon nanoparticles (stock concentration- $2 \mathrm{mg} / \mathrm{ml}$ ) and incubated for $2 \mathrm{hrs}$. Then $20 \mu \mathrm{l}$ of treated RBC was placed on a clean slide. The images were taken with fluorescence microscope.

\section{Cell labelling of MDA-MB-468 using CNPs}

Cells were seeded in $35 \mathrm{~mm}$ experimental plates containing $18 \mathrm{~mm}$ coverslip. Treatment was done with $20 \mu \mathrm{g} / \mathrm{ml}$ carbon nanoparticles and was incubated for $24 \mathrm{hrs}$. The plates were then thoroughly washed with phosphate buffer saline and the cover slip was carefully placed on a clean slide using $50 \%$ glycerol as a mounting medium. The mounted cover slip was then properly sealed and the images were taken with the help of fluorescent microscope.

\section{Statistical analysis}

We repeated these experiments three times and the data were expressed by calculating the standard deviation of all the experiments. The data is the average of three experiments \pm SD.

\section{Results \& Discussion}

\section{Morphological and structural charecterisations of carbon nanoparticle}

Figure.1a. represent the X-ray diffraction (XRD) of CNPs intense peak at $2 \theta=22.60^{\circ}$ and a weak peak at $2 \theta=40.80^{\circ}$ that corresponds to the diffraction patterns of graphitic carbon [24]. The XRD spectra confirm the formation of carbon nanoparticles. 
FTIR spectra of the carbon nanoparticles are depicted in Figure.1b. Here, the peak that appeared at $1520 \mathrm{~cm}^{-1}$ is assigned to the characteristics backbone $\mathrm{C}=\mathrm{C}$ skeletal stretching of $\mathrm{CNPs}$, while the absorption bands at $1650 \mathrm{~cm}^{-1}$ and $1230 \mathrm{~cm}^{-1}$ are associated with $\mathrm{C}-\mathrm{C}$ vibrations and $\mathrm{C}-\mathrm{O}$ stretching vibration, corresponding to the internal defects of carbon nanoparticles [25].

\section{Figure.1.}

(a)

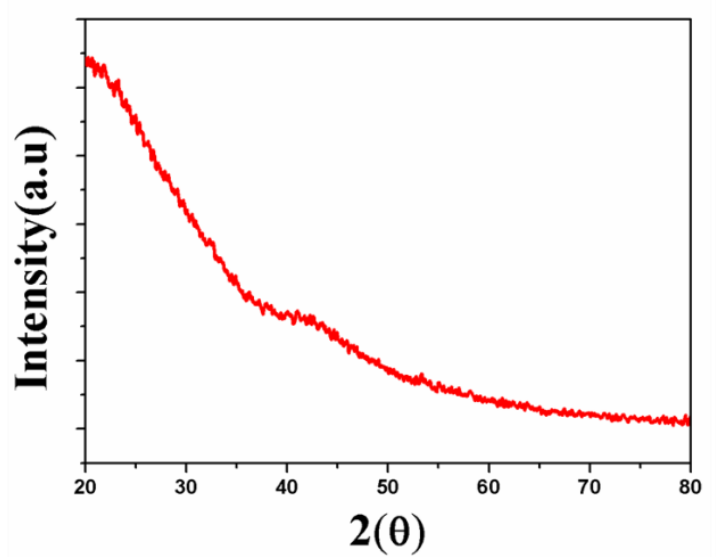

(b)

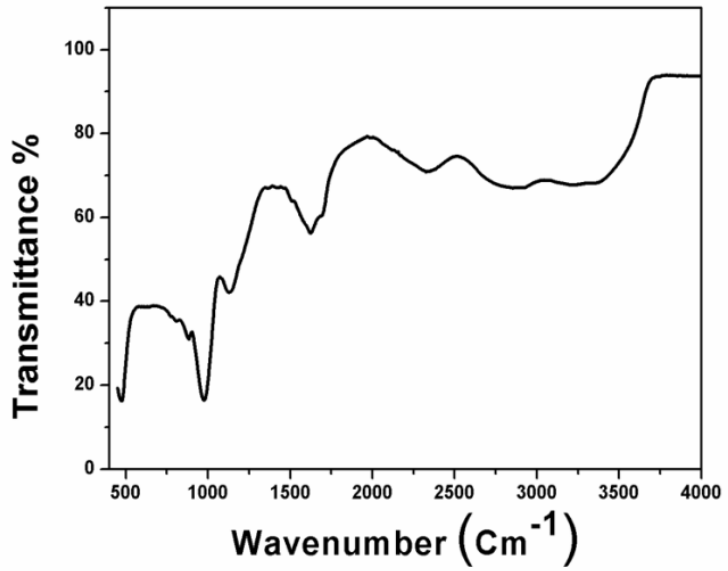

Figure 1.(a). XRD and (b) FTIR analysis of carbon nanoparticles

\section{UV-Vis analysis of carbon nanoparticle}

CNPs showed the highest characteristic fluorescence peak at $450 \mathrm{~nm}$ excitation wavelength and the peak was extremely broad as seen in Figure.2a.The carbon nanoparticles emit prominent green fluorescence as seen in Figure.2b. 
Figure.2.

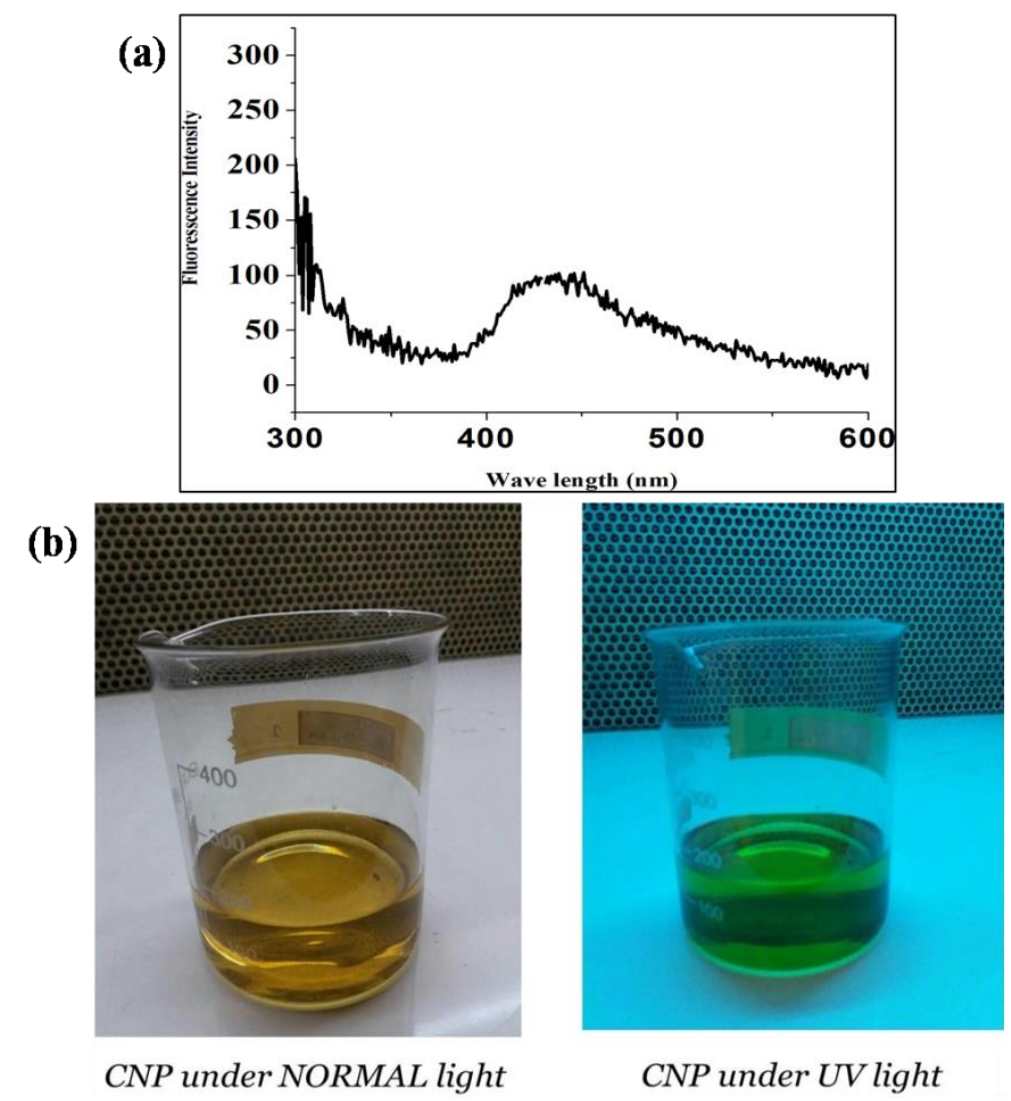

Figure 2.(a). UV-Vis analysis of carbon nanoparticles, (b) Carbon nanoparticle emit green fluorescence under UV light

\section{Hydrodynamic size and zeta potential assessment of carbon nanoparticles}

The size of the CNP was determined by DLS Table.1. As seen from Figure.3.(a) average hydrodynamic size of CNPs was $281.2 \mathrm{~d} . \mathrm{nm}$. The zeta potential of CNPs was determined by zetasizer. The zeta potential of CNPs was found to be-39.7mV at pH 7. (Fig.3.b). Due to this high negative zeta potential of the microsphere the carbon nanoparticles are stabilized. The corresponding polydispersity index (PDI) values of the samples are quite low suggesting that they form a homogenous solution which is desirable for any biological application.

Table.1. Determination of hydrodynamic size and surface charge of synthesized CNPs

Sample name DLS size PDI value Zeta Potential

CNP $\quad 281.22($ d.nm $) \quad 0.277 \quad-39.7(\mathrm{mV})$


Figure.3.

(a)

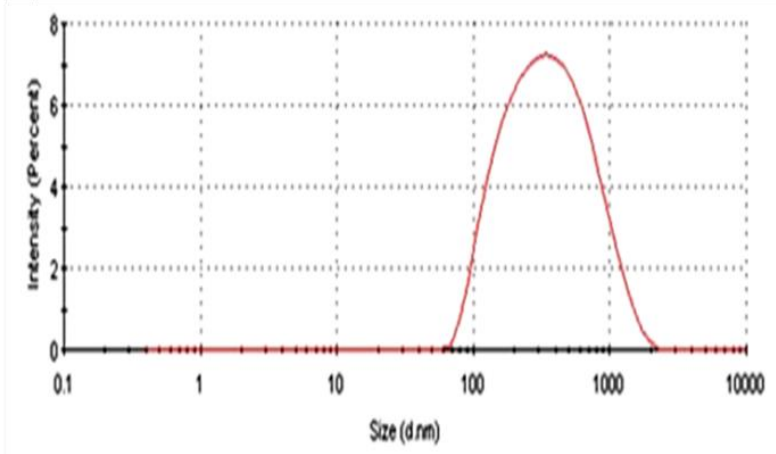

(b)

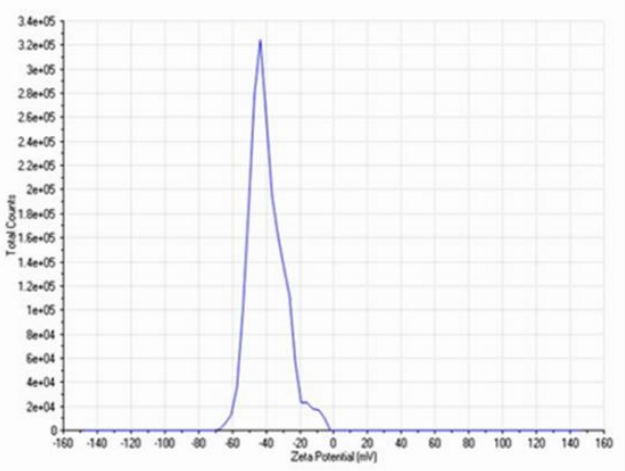

Figure 3.(a). Hydrodynamic size of carbon nanoparticles, (b) Zeta potential of carbon nanoparticles.

\section{Biological assessments}

(a) Carbon nanoparticles do not show any significant antibacterial activity

It was observed that there was considerable bacterial growth in spite of carbon nanoparticle treatment even at the highest concentration of $500 \mu \mathrm{g} / \mathrm{ml}$. Hence we can conclude that carbon nanoparticle showed no significant antibacterial activity against pathogenic Gram negative bacterial strain, E.coli and Gram positive S.aureus strain as seen in Figure 4a and 4b. 
Figure.4.

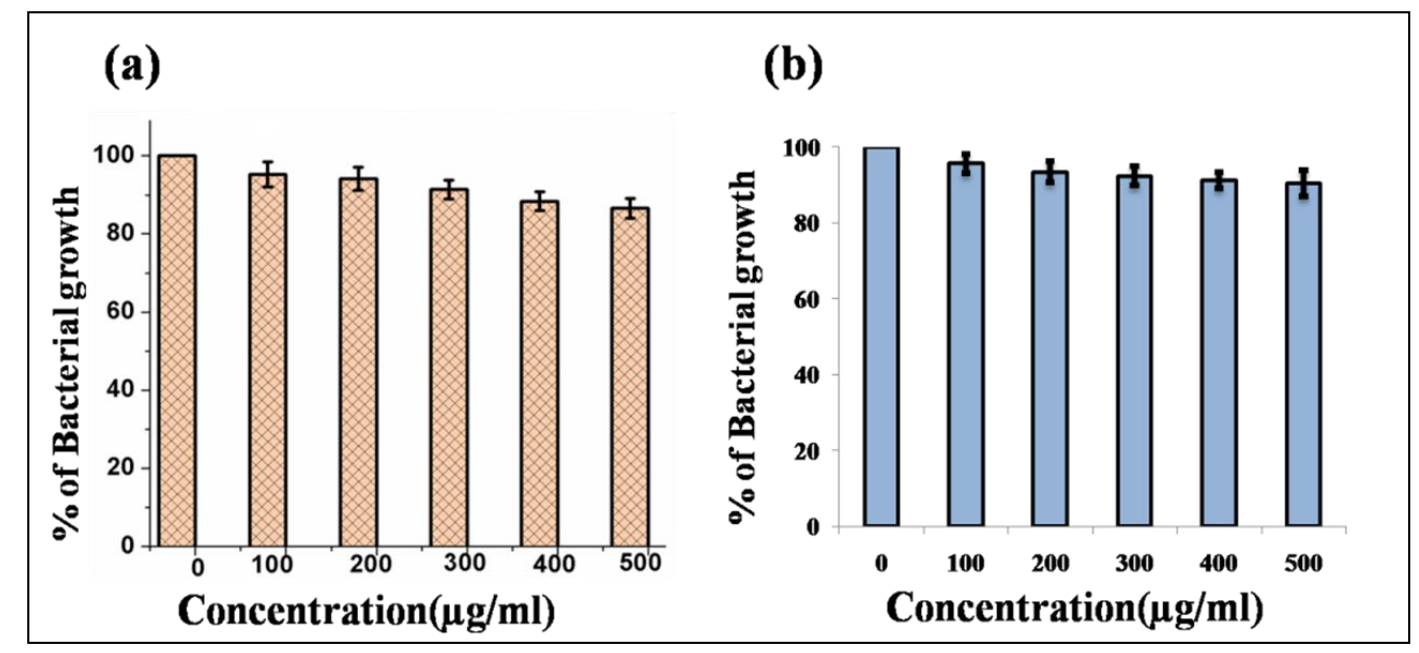

Figure.4. Bacterial activity assessment of carbon nanoparticles against (a) $E$. coli and (b) $S$. aureus pathogenic bacterial strains.

\section{Carbon nanoparticles show excellent biocompatibility}

A concentration dependent study was conducted to find out the effects of carbon nanoparticles on breast cancer cells, MDA-MB-468 and normal lung fibroblast cells, WI38. It was seen that there was no considerable change in the survivability of the cells even at higher concentrations of $200 \mu \mathrm{g} / \mathrm{ml}$ and $300 \mu \mathrm{g} / \mathrm{ml}$ in case of both the cell lines as seen in Figure.5a and $5 \mathrm{~b}$. Thus we can conclude that the carbon nanoparticles do not exert significant anticancer activity but it also possesses remarkable compatibility towards the normal cells. This biocompatiblitily is quite conducive for application in therapeutic purposes.

\section{Figure.5.}

(a)

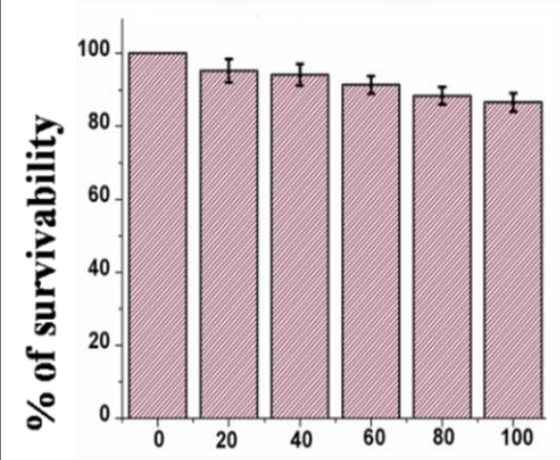

Concentration $(\mu \mathrm{g} / \mathrm{ml})$ (b)

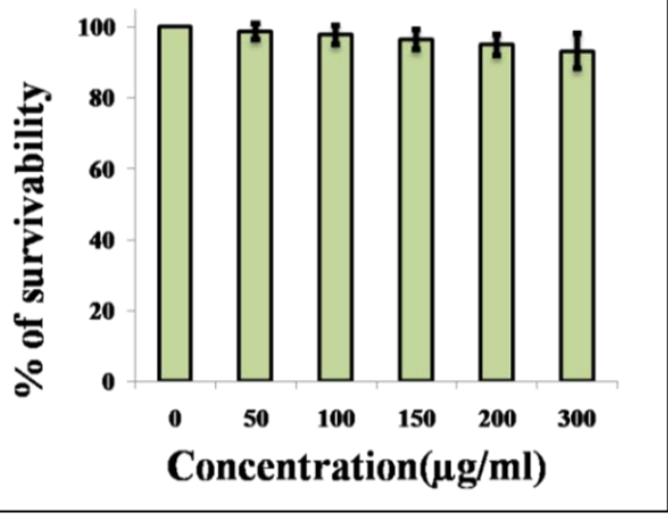

Concentration $(\mu \mathrm{g} / \mathrm{ml})$

Figure.5. Cell survivability evaluation of carbon nanoparticles on (a) WI-38 cells and (b) MDA-MB 468 cells. 
Carbon nanoparticles can be utilized as biological tools for visualization of Human RBCs and cancer cells

The fluorescence microscopic image sug considerable carbon nanoparticle uptake inside the RBC as seen in Figure 6a.The fluorescence microscope images suggest a considerable cellular uptake of carbon nanoparticles in human breast cancer cell line MDA-MB-468 (Figure 6b). This suggests that the carbon nanoparticles even without functional modifications are able to internalize within internal mileu of the RBCs and the breast cancer cells which results in the appearance of prominent green fluorescence within these cells. On the other hand the untreated cells fail to exhibit any such fluorescence. Hence the carbon nanoparticles can emerge as promising biolabelling intervention for future biomedical applications.

Figure.6.

(a)
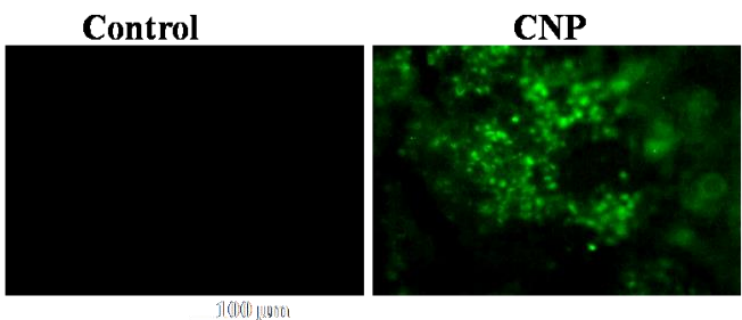

(b)
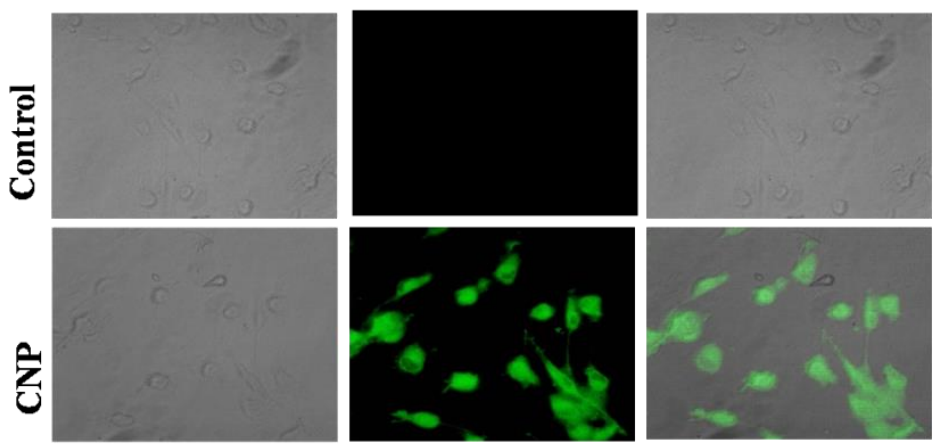

Figure.6. Bioimaging assays with the help of fluorescent carbon nanoparticles in (a) Human RBCs and (b)MDA-MB 468 cells

\section{Conclusions}

Carbon nanoparticles synthesized through an inexpensive, facile method with mean hydrodynamic size 281.2 d.nm show significant fluorescence property. The carbon nanoparticles did not show any considerable anticancer and antibacterial activity. However these nanoparticles possess excellent biocompatibility towards the normal cells. Because of the low size, it can easily penetrate within the breast cancer, MDA MB 468 cell line and erythrocyte enriched fraction of human blood cells, giving a 
bright green fluorescence under the fluorescence microscope. From our study, we have concluded that our synthesized non-toxic fluorescent carbon nanoparticle can be used for bioimaging application for cancer cell and Human RBCs. This attribute can be further explored for applications in different biomedical areas.

\section{References}

1. Sun Y.P, Zhou B, Lin Y, Wang W, Fernando K.A.S, Pathak P, Meziani M.J, Harruff B.A, Wan X, Wang H, Luo P.G, Yang H, Kose M.E, Chen B, Veca L.M, Xie S.Y. J. Am. Chem. Soc. (2006) 128 7756.

2. Gao L, Wang X, Meziani M.J, Lu F, Wang H, Luo P.G, Lin Y, Harruff B.A, Veca L.M, Murray D, Xie S.Y, Sun Y.P.J, Am. Chem. Soc. (2007) 12911318.

3. Liu H Ye T, Mao C. Angew. Chem. Int. Ed. (2007) 466473.

4. Zhao Q.L, Zhang Z.L, Huang B.H, Peng J, Zhang M, Pang D.W. Chem.Commun. (2008) 415116.

5. Selvi B.R, Jagadeesan D, Suma B.S, Nagashankar G, Arif M, Balasubramanyam K, Eswaramoorthy M, Kundu T.K. Nano Lett. (2008) 83182.

6. Bourlinos A.B, Stassinopoulos A, Anglos D, Zboril R, Georgakilas V, Giannelis E.P. Chem.Mater. (2008) 204539.

7. Mochalin V.N, Gogotsi Y.J. Am. Chem. Soc. (2009) 1314594.

8. Liu R, Wu D, Liu S, Koynov K, Knoll W, Li Q. Angew. Chem. Int. Ed. (2009) 48(25) 4598.

9. Ushizawa K, Sato Y, Mitsumori T, Machinami T, Ueda T, Ando T. Chem.Phys. Lett. (2002) 351 105.

10. Huang L.C.L, Chang H.C. Langmuir 2004205879.

11. Kong X.L, Huang L.C.L, Hsu C.M, Chen W.H Han C.C, Chang H.C. Anal. Chem. (2005) 77259.

12. Medintz I.L, Uyeda H.T, Goldman E.R, Mattoussi H. Nat. Mater. (2005) 4435.

13. Yezhelyev M.V, Gao X, Xing Y, Al-Hajj A, Nie S, O’Regan R.M. Lancet Oncol (2006) 7(8) 657.

14. Kong X, Huang L.C.L, Liau S.C.V, Han C.C, Chang H.C. Anal. Chem. (2005) 774273.

15. Jain K.K. Expert opin pharmacother (2005) 6(9) 1463.

16. Chan P, Yuen T, Ruf F, Gonzalez-Maeso J, Sealfon S.C. Nudeic Acids Res (2005) 33(18) e161. 
17. Fortina P, Kricka L.J, Surrey S, Grodzinski P. Trends Biotechnol (2005) 23(4) 168.

18. Gao X, Cui Y, Levenson, R.M, Chung L.W.K, Nie S. Nat Biotechnol (2004) 22(8) 969.

19. Artemov D, Mori N, Okollie B, Bujwalla Z.M. Magn Reson Med (2003) 49(3) 403.

20. Suganeswari M, M Shering A, Bharathi P, Jayasutha J. International Journal of Pharmaceutical \& Biological Archives (2011) 2(2) 847.

21. Kahru A, Kasemets K, Ivask A, Blinova I, Bondarenko O, Mortimer M, Heinlaan M, Käkinen A, Aruoja V. Nordic NanoNet Workshop and EDC discussion (2011) 11133.

22. Franklin N.M, Rogers N.J, Apte S.C, Batley G.E, Gadd G.E, Casey P.S. Environ. Sci. Technol. (2007) 418484.

23. Osborne C.K. The New England Journal of Medicine (1998) 339(22) 1609.

24. Karlsson H.L, Cronholm P, Gustafsson J, Möller L. Chem Re oxicol (2008) 91726.

25. Prasad B.S.N, Padmesh T.V.N, Suganya K.S.U, Govindaraju K, Kumar G.V. Journal of Environment and Biotechnology Research (2016) 3(1) 12.

26. Muhammad Azhar Hayat Nawaz, Rauf S, Catanante G, Nawaz M.H, Nunes G, Marty J.L, Akhtar H. Sensors (2016) 161651.

27. Bardhan S, Pal K, Roy S, Das S, Chakraborty A, Karmakar P, Basu R, Das S. Journal of Nanoscience and Nanotechnology (2019) 19(11) 7112.

28. Bera D, Pal K, Bardhan S, Roy S, Parvin R, Karmakar P, Nandy P, Das S. Advances in Natural Sciences: Nanoscience and Nanotechnology ((2019) 10(4), 045017.

29. Bera D, Pal K, K P, Das S, Nandy P. Sciforum MOL2NET 6 (2020).

30. Pal K, Roy S, Parida P.K, Dutta A, Bardhan S, Das S, Jana K, Karmakar P. Materials Science \& Engineering C (2019) 95204.

31. Manna T, Pal K, Jana K, Misra A.K, Anti-cancer potential of novel glycosylated 1,4-substituted triazolylchalcone derivatives Bioorg Med Chem Lett (2019) 29(19) 126615. 